\title{
Cutaneous sporotrichosis as an occupational disease: Case report
}

\author{
César Bimbi ${ }^{1,2}$, Piotr Brzezinski ${ }^{3,4}$ \\ ${ }^{1}$ Brazilian Society of Dermatology, ${ }^{2}$ Institute of Dermatology, Centro Historico, Porto Alegre, Brazil, ${ }^{3}$ Department of \\ Cosmetology, Institute of Biology and Environmental Protection, Pomeranian Academy, Slupsk, Poland, ${ }^{4}$ Department of \\ Dermatology, $6^{\text {th }}$ Military Support Unit, Ustka, Poland
}

Corresponding author: Dr. César Bimbi, E-mail: cbimbi@terra.com.br

\begin{abstract}
Subcutaneous mycoses are not rare in Latin America. In Brazil, sporotrichosis was once almost exclusively found in rural areas, but in recent years it changed its profile and has been more frequent among urban adults. Cutaneous sporotrichosis is acquired from saprophytic dimorphic fungus Sporothrix schenckii usually found in soil, vegetation, and especially decaying organic matter in tropical, subtropical, and humid environments through cutaneous inoculation. The fungus abundantly grows on dead wood. Sporotrichosis is a health hazard present in florists, gardeners and other urban professions in contact with plants and the infection is increasingly seen as an occupational disease. The patient had been hurt in the finger by a thorn of Bouganvillea tree and a primary ulcer started.
\end{abstract}

Key words: Sporotrichosis; Occupational; Thorn cut

\section{INTRODUCTION}

Sporotrichosis is a subcutaneous mycosis subacute or chronic evolution, caused by the dimorphic Sporothrix complex, which includes five species: Sporothrix albicans, Sporothrix brasiliensis, Sporothrix globosa, Sporothrix Mexicana and Sporothrix schenckii (sensu stricto). The infection occurs after trauma with contaminated material, which inoculated the fungus on the skin. The clinical types of sporotrichosis are lymphocutaneous sporotrichosis, fixed cutaneous (nodulopapular, ulcerative, verrucouse and furunculoide) and extracutaneous [1,2].

\section{CASE REPORT}

An otherwise healthy 40 years old man resident in the metropolitan area of Porto Alegre, southern Brazil, came to the office with a history of a 3 weeks ulcerated lesion in the index finger of the right hand and a wrist nodosity. The patient had been hurt in the finger by a thorn of Bouganvillea tree (Fig. 1) and a primary ulcer started (Fig. 2). The primary lesion developed at the index finger, that was the site of inoculation, and it was followed some days later by subcutaneous nodules on the wrist that progressed along lymphatic channels. His profession was a condominium caretaker and he was in charge of gardening services. The mycological culture showed leathery wrinkled colonies progressively darker typical of Sporothrix schenckii. All lesions resolved after treatment with oral itraconazole $200 \mathrm{mg} / \mathrm{d}$. The treatment usually lasts for 3-6 months (Fig. 3).

\section{DISCUSSION}

The lymphocutaneous form is the classical presentation of sporotrichosis. The primary lesion develops at the site of skin inoculation, commonly hands and arms. After some days to weeks it progresses to nodules along the lymphatic tract [2]. Patients are otherwise healthy, afebrile and well. Self-healing cases sometimes happen. Antibiotics are commonly prescribed in this phase as it mimics staphylococcal infections. When left untreated 


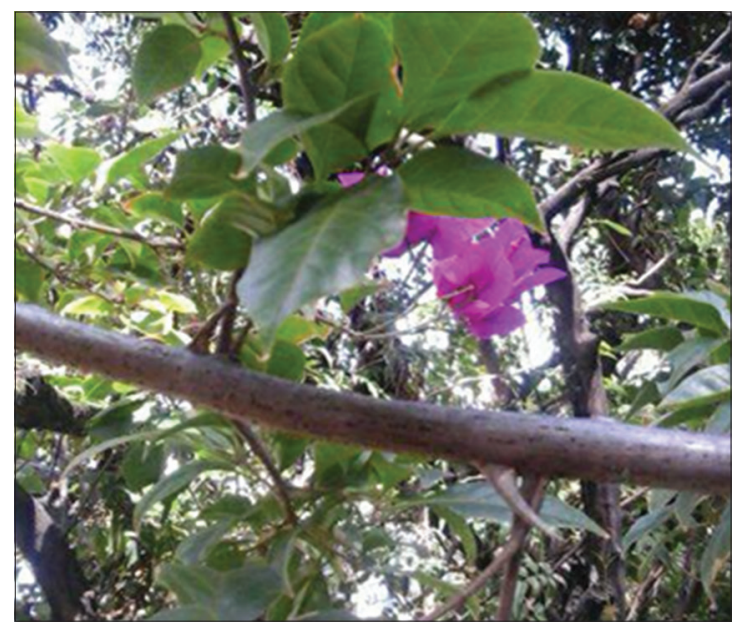

Figure 1: Bougainvillea tree and a thorn of ornamental Bougainvillea tree.

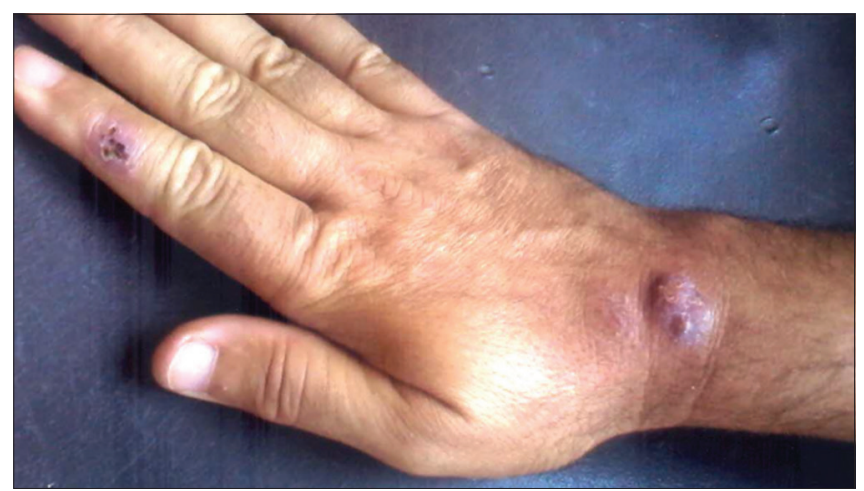

Figure 2: The primary lesion developed at the index finger, as a site of inoculation, and subcutaneous nodules on the wrist as a progressed along lymphatic channels some days later.

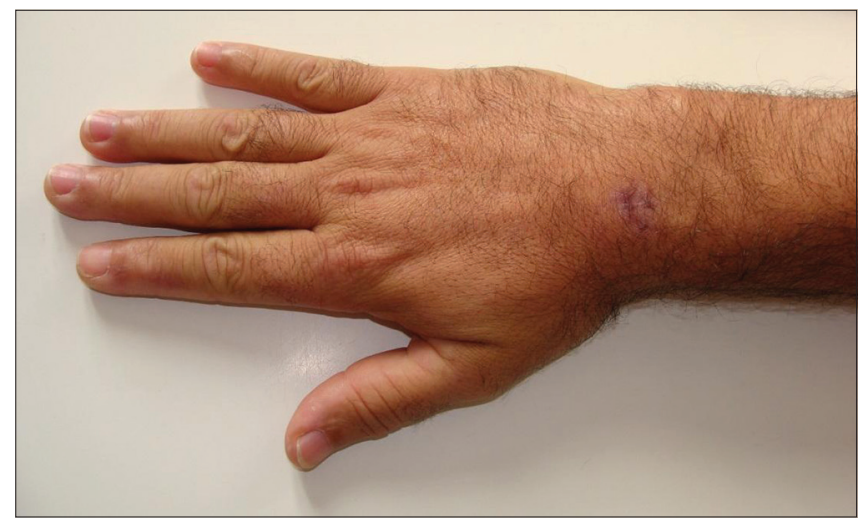

Figure 3: After treatment with oral itraconazole $200 \mathrm{mg} / \mathrm{d}$.

it follows a chronic course although the ulcerated inoculative lesion may heal spontaneously.

Fixed and disseminated forms are other rarer cutaneous variants.

Systemic sporotrichosis is the result of conidia inhalation or hematogenous dissemination from primary sites but (c) Our Dermatol Online 1.2017 is also rare. In a large outbreak that occurred in gold mines of South Africa in more than 3000 miners, none of them had disseminated disease. Pulmonary sporotrichosis via inhalation of Sporotrichum displays a form radiographically indistinguishable from tuberculosis and histoplasmosis in patients with severe underlying chronic obstructive pulmonary disease and alcoholism [2,3]. Granulomatous tenosynovitis and carpal tunnel syndrome have also been described [4]. Osteoarticular sporotrichosis may result from direct inoculation or hematogenous disseminated S. schenckii, with an involvement of multiple visceral organs; this occurs almost exclusively in persons with AIDS.

The hyperendemicity areas of certain countries and high numbers in certain populations are still unexplained. Before the Great War, many cases of the disease occurred in France but after a while, the incidence declined abruptly.

Peruvian Andes villages show the incidence of sporotrichosis as approximately 1 case per 1000 people. Epidemics have been described in western Australia, China and the large outbreak occurred in gold mines of South Africa in more than 3000 miners who had frequent physical contact with wood timber supports. In Uruguay, armadillo hunting is a high-risk activity [5].

The fungus S. schenckii grows abundantly on dead wood but it has never been observed as plant pathogens, probably due to the antifungal activity of plants. The fungus grew best on Acacia melanoxylon, Cinnamomum camphora, Eucalyptus grandis, E. sideroxylon, and Ginkgo biloba [6,7]. This patient had been hurt while trimming Bougainvillea spp. It is a tree native to Brazil and is a fast-growing plant that creates a colorful barrier - are perennials with profuse and blooms and rapid growth and prized for security features because of sharp thorns that can easily pierce through the fabric and into bare skin. Must be regularly trimmed to prevent it from growing out of control.

In Brazil in the 50`s, 93\% of sporotrichosis patients were from rural areas [8], but lately the disease changed its profile and is becoming more frequent among urban adults and as an occupational disease. Decaying vegetable matter of high humidity areas with temperatures between 16 and $20 \mathrm{oC}$ seem to be the ideal conditions for the fungus proliferation. Splinter and thorns are favorite habitats and favor the growth of fungus. Florists, gardeners, forestry workers, miners and people who deal with soil are workers at greatest risk. 


\section{www.odermatol.com}

Domestic cats are frequent transmitters, by scratch. Also but rarely, cattle, dogs, horse, camel, swine, rat, mouse, lizard, chimpanzee and dolphin have been described.

Antifungal therapy is the mainstay of treatment for all forms of sporotrichosis. Itraconazole is the best drug for cutaneous sporotrichosis. Heat application to lesions may help since low temperatures are preferred by the fungus.

Wearing gloves and other protective clothing when gardening or handling animal especially cats are necessary as preventive methods against the infection.

\section{REFERENCES}

1. Ramírez Soto MC. Facial Sporotrichosis in children from endemic area in Peru. Our Dermatol Online. 2013;4:237-40.

2. Marques GF, Martins AL, Sousa JM, Brandão LS, Wachholz PA, Masuda PY. Characterization of sporotrichosis cases treated in a dermatologic teaching unit in the state of São Paulo - Brazil, 2003 - 2013. An Bras Dermatol. 2015;90:273-5.
3. Queiroz-Telles F, Nucci M, Colombo AL, Tobón A, Restrepo A Mycoses of implantation in Latin America: an overview of epidemiology, clinical manifestations, diagnosis and treatment. Med Mycol. 2011;49:225-36

4. Watanabe M, Hayama K, Fujita H, Yagoshi M, Yarita K, Kamei K, et al. A Case of sporotrichosis caused by sporothrix globosa in Japan. Ann Dermatol. 2016;28:251-2.

5. Lyon GM, Zurita S, Casquero J, Holgado W, Guevara J, Brandt ME, et al. Population-based surveillance and a case-control study of risk factors for endemic lymphocutaneous sporotrichosis in Peru. Clin Infect Dis. 2003;36:34-9.

6. Mahajan VK. Sporotrichosis: an overview and therapeutic options. Dermatol Res Pract. 2014;2014:272376.

7. Almeida-Paes R, de Oliveira MM, Freitas DF, do Valle AC, Zancopé-Oliveira RM, Gutierrez-Galhardo MC. Sporotrichosis in Rio de Janeiro, Brazil: Sporothrix brasiliensis is associated with atypical clinical presentations. PLoS Negl Trop Dis. 2014;8:e3094.

8. Almeida F, Sampaio Sap Lacaz CS, Fernan-Des JC - [Statistical data on sporotrichosis; analysis of 344 cases]. An Bras Dermatol Sifil. 1955;30:9-12.

Copyright by César Bimbi, et al. This is an open access article distributed under the terms of the Creative Commons Attribution License, which permits unrestricted use, distribution, and reproduction in any medium, provided the original author and source are credited.

Source of Support: Nil, Conflict of Interest: None declared. 